\title{
Bárbara Andrez
}

barbaraandrez@gmail.com

Infocomunicação em museus: uma reflexão à luz do paradigma da complexidade de Edgar Morin. 
Andrez, B. (2021). Infocomunicação em museus: uma reflexão à luz do paradigma da complexidade de Edgar Morin. In P. M. Homem, B. Andrez, G. Soares, \& L. Amaral (Eds.), Ensaios e Práticas em

Museologia (Vol. 10, pp. 131-141). Porto: FLUP/DCTP/MMUS. https://doi.org./10.21747/978-9899082-06-9/102021a8

Resumo

A presente reflexão pretende introduzir, de forma sucinta, uma abordagem sistémica da infocomunicação no contexto das instituições museológicas. Partindo da premissa que as ações museológicas e os mecanismos expositivos não são atividades neutras, mas relevantes para a representação e comunicação das relações que se estabelecem entre sociedades e tempos a partir dos objetos expostos, reflete-se sobre a sua importância e adequação. Alicerçados no paradigma da complexidade de Edgar Morin, procede-se a um primeiro enunciado de possíveis fatores - internos e externos - que influenciam os processos de informação e de comunicação dentro e fora dos museus, bem como a identificação de algumas relações e potenciais eixos de ação.

Palavras-chave: Complexidade; Infocomunicação; Fatores de influência; museus

\section{Nota biográfica}

Bárbara Andrez é licenciada em Estudos Teatrais pela Escola Superior de Música e de Artes do Espetáculo (ESMAE), mestre em Criação Artística

Contemporânea pela Universidade de Aveiro Departamento de Comunicação e Arte (UA/DeCA) e mestre em Museologia pela Faculdade de Letras da Universidade do Porto (FLUP). Atualmente é bolseira de investigação FCT/CITCEM no programa doutoral em Informação e Comunicação em Plataformas Digitais, curso conjunto da FLUP e UA/DeCA. Trabalhou como técnica superior de ação cultural e espetáculos na Câmara Municipal de Ovar e, entre 2016 e 2021, colaborou como museóloga para a Associação dos Antigos Alunos da Escola Oliveira Lopes, no Museu Escolar Oliveira Lopes em Válega, Ovar, onde para além da normal prática museológica, foi a impulsionadora da criação de um serviço educativo.

\section{Abstract}

This reflection intends to introduce, in a succinct way, a systemic approach to infocommunication in the context of museological institutions. Grounded on the premise that museological actions and exhibition mechanisms are not neutral activities, but relevant for the representation and communication of the relationships established between societies and eras that rely upon the exhibited objects, one reflects on their importance and adequacy. Based on Edgar Morin's paradigm of complexity, a first statement of possible factors - internal and external that influence the information and communication processes inside and outside museums is uttered, as well as the identification of some relationships and potential axes of action.

Keywords: Complexity; Infocommunication; Influencing factors; museums

\section{Biographical note}

Bárbara Andrez has a degree in Theatrical Studies from the Superior School of Music and Performing Artes (ESMAE) and holds a master in Contemporary Artistic Creation from University of Aveiro Department of Communication and Art (UA/DECA) and a master in Museology from University of Porto Faculty of Arts. She is currently a FCT/CITCEM research fellow in the doctoral programme in Information and Communication in Digital Platforms, a joint course of FLUP and UA/DeCA. She worked in cultural action and production in Ovar's city hall and, between 2016 and 2021, collaborated as a museologist for the Oliveira Lopes Old Students Association in the Oliveira Lopes School Museum in Válega, Ovar, where, besides the normal museological activity, she created an educational service. 


\section{Da infocomunicação à definição de museu}

De uma forma geral, os museus, como repositórios da memória coletiva, sempre se constituíram das interações permanentes com a sociedade onde se inserem. É inegável, portanto, esta capacidade de algumas instituições, quase metamorfósica, que lhes permite adequar a comunicação e a disseminação das suas coleções à realidade. Porém, há que antever que, face a qualquer alteração, será sempre necessária uma visão museológica holística e integrada, baseada em dinâmicas estratégicas e equipas interdisciplinares que deverão ser equacionadas regularmente e em confrontação direta com os contextos específicos.

Falar de museus e dos processos infocomunicacionais que lhes estão subjacentes parece uma redundância, uma vez que a palavra comunicação surge espelhada no próprio conceito de museu. Segundo o Internacional Council of Museums (ICOM) o museu é uma instituição permanente sem fins lucrativos, ao serviço da sociedade e do seu desenvolvimento, aberta ao público, que adquire, conserva, investiga, comunica e expõe o património material e imaterial da humanidade e do seu meio envolvente com fins de educação, estudo e deleite (ICOM Portugal, 2015).

Não obstante, o que define estes processos infocomunicacionais e como compreendêlos?

Antes de mais, convém entender que a palavra processo abarca uma série de significados. Reportando ao dicionário Collins e ao dicionário Cambridge, processo identifica um método ou sistema (Collins, 2021) ou uma série de ações humanas ou alterações naturais que permitem que algo aconteça (Cambridge University Press, 2021). Por outro lado, a palavra infocomunicação advém da junção de dois conceitos que se interligam: informação e comunicação.

De acordo com Silva (2010) “O conceito de informação convoca (...) o de comunicação e ambos se reportam a um fenómeno humano e social que tem a ver com a capacidade simbólica de cada pessoa e com a necessidade de interação" (p. 115). 
Convém demarcar que, apesar de os conceitos se interligarem, informação não é comunicação, existindo uma relação intersubjetiva, em sintonia com Passarelli et al. (2014). Para estes autores, informação diz respeito a uma ordem do conteúdo, enquanto a comunicação proporciona uma ordem de relação, com vista à fabricação de um sentido, mas a "comunicação não corresponde em si a um fenómeno meramente social e cultural, ela é inseparável da dimensão informacional" (Gouveia \& Silva, 2020, p.29)

Silva (2006) reporta-se ainda à informação como um "conjunto estruturado de representações mentais e emocionais codificadas (...) e modeladas com/pela interaç̧ão social, passíveis de serem registadas num qualquer suporte material" ( $p$. 150). Quanto ao conceito de comunicação, considera que representa o "processo de transmissão de informação entre agentes que partilham um conjunto de signos e de regras semióticas (...) tendo como objectivo a construção de sentido (...) e pressupõe necessariamente informação sob a forma de mensagens ou conteúdos transmitidos" (p. 143).

Na translação destes conceitos para as instituições museológicas é de fácil compreensão que, em cada contexto, existirá naturalmente uma ordem na informação/conteúdo que ao longo dos anos foi produzido e a forma como a informação é comunicada será sempre variável, mediante o âmbito de cada uma das instituições. Não obstante, é necessário entender que estes processos infocomunicacionais adensam-se com as flutuações e fenómenos que ocorrem dentro e fora das próprias instituições. 


\section{Da complexidade aos fatores de influência}

Quando se definem e iteram os processos infocomunicacionais dentro das instituições museológicas, é necessário um pensamento transdisciplinar e sistémico que permita uma abertura dos mecanismos, decompondo possíveis relações, adicionando ou subtraindo, conforme cada caso específico.

Segundo Morin (2005), pensar nestas dependências é percecionar relações complexas no desenho de um paradigma, que se intitula complexidade. Afinal, o que é a complexidade e como podemos adequá-la aos processos infocomunicacionais em museus? Morin (2005) define a complexidade como um conjunto de "interações e de interferências entre um número muito grande de unidades (...) incertezas, indeterminação, fenômenos aleatórios" (p. 35), mas esta complexidade "não se reduz à incerteza, é incerteza no seio de sistemas ricamente organizados" (p. 35).

Percecionar os museus como sistemas complexos é compreender que eles se organizam e atuam dentro de um determinado ambiente e contexto(s) específico(s) e de acordo com uma intencionalidade orgânica. Por isso, é importante antever que as especificidades subjacentes a cada instituição museológica influenciam os seus processos infocomunicacionais, as suas interações/ações, uma vez que fatores internos e externos que decorrem do(s) contexto(s) interferem na gestão da informação, da metainformação e da transmissão de conhecimento relativo a objetos/artefactos que primam pela sua materialidade e a criações como instalações, performance, videoarte ou mapping que salientam a dimensão conceptual (e remetem para o mentefacto do artista/criador), e, em última instância, na forma como estes são expostos e comunicados. Assim, quando se desenham as ações de comunicação em instituições museológicas, será sempre necessária uma visão ampla e informada destes fatores de influência e inerente olhar sistémico que faça emergir problemas/necessidades, nomeadamente no que diz respeito ao estudo e gestão das coleções, ao papel do produtor/artista/criador, à constituição das equipas, aos visitantes, à gestão dos recursos, aos equipamentos e coleções, ao orçamento, ao 
organograma, entre muitos outros fatores tais como: os stakeholders, as leis e definições orgânicas do país, a promoção do turismo, o ambiente, contexto e sociedade onde se inserem, bem como as interações latentes com a comunidade.

O esquema apresentado na Fig. 1 constitui uma primeira sistematização de possíveis fatores internos e externos que decorrem da influência do paradigma da complexidade em museus. De notar que visitantes e stakeholders apresentam-se no grupo de influência interna e externa. Isto prende-se com a capacidade participativa e de integração de cada instituição com as suas comunidades. Quando se trata de um ecomuseu por exemplo, visitantes e stakeholders expressam-se no interior das instituições, porque a premissa e apelo à participação se adequa à missão do museu. 0 mesmo acontece com outras instituições, onde os visitantes são integrados como participantes ativos nas ações. Porém não se deve deixar de considerar que, em muitos museus, esta relação de influência será apenas externa. 


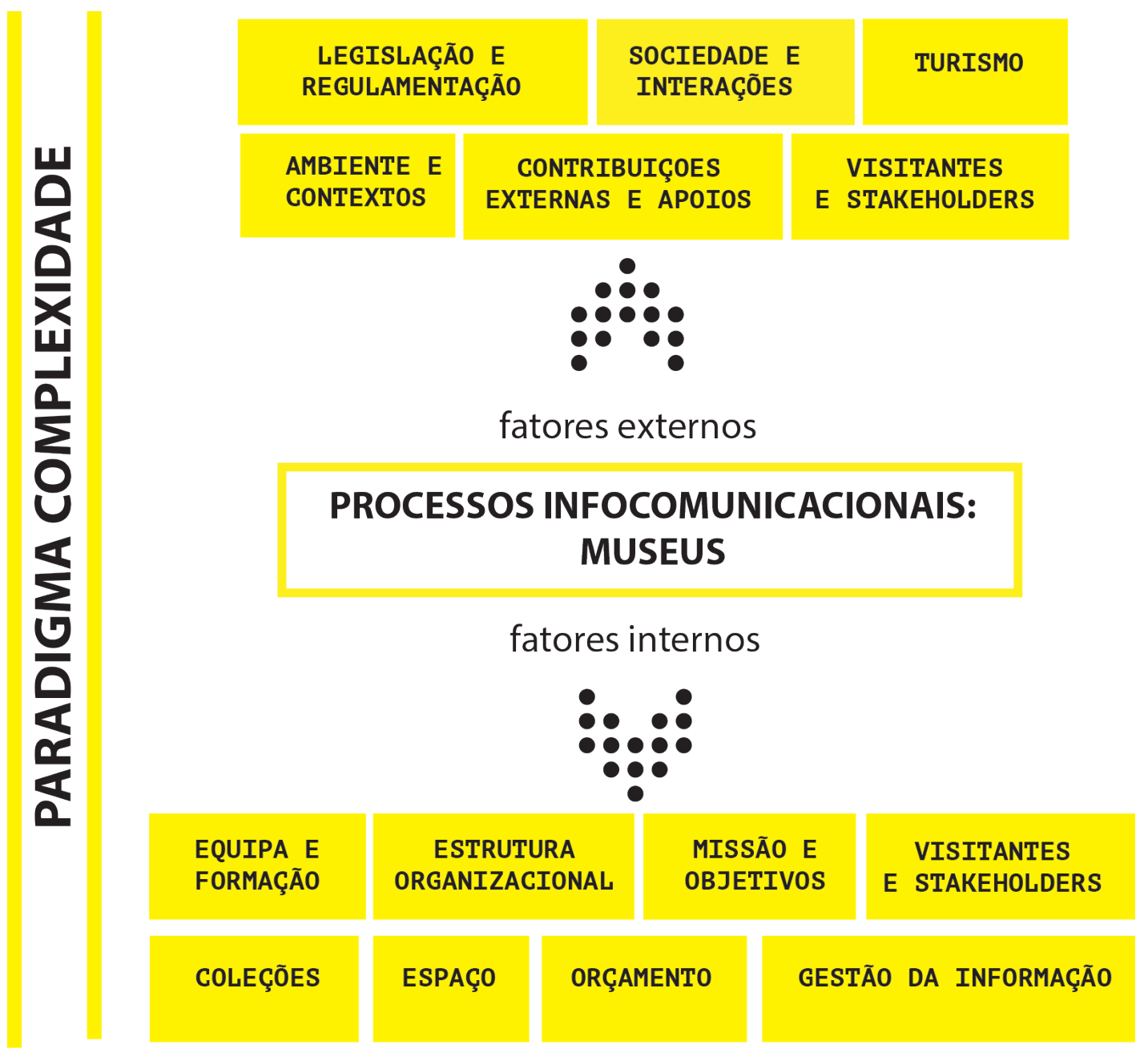

Fig. 1 - Esquema de possíveis relações dos processos infocomunicacionais em museus e o paradigma da complexidade. CBárbara Andrez, 2021.

A inclusão das Tecnologias da Informação e Comunicação (TIC) em ambientes museológicos, por exemplo, proporcionou uma produção e gestão da informação relativa às coleções que contribuiu para uma sistematização da informação relevante. Porém, por si só, essa informação não é geradora, nem sinónimo, de comunicação. A aquisição e uso de softwares que permitem esta gestão informacional, apenas conduzem a uma melhoria na procura, no sistema de filtros e na agregação de documentos e outros conteúdos relacionados com determinado objeto que, no caso de uma exposição, ação de serviço educativo, ou outra, necessitará de ser comunicada. 
Concordando que "Informer n'est pas communiquer" (Wolton, 2009), a informação e metainformação que estes sistemas contêm, ou outros semelhantes, irá sofrer sempre uma segregação à volta de um sentido ou propósito, muitas vezes não plenamente consciente, provida pelas mãos de um curador, de um museólogo, de um educador ou até de um conservador. Indo mais longe, como todas as instituições museológicas se constituem como sistemas orgânicos as suas coleções apresentam, também elas, os seus próprios contextos, identificando-se como sistemas dentro de sistemas. Acresce que, segundo Pearce (1994), os objetos existem numa relação espacial com outros objetos e paisagens e o estudo destas relações é benéfico para os entender e comunicar. Assim, a biografia dos objetos pode constituir-se como uma fonte informacional relevante e simbólica (Kopytoff, 1986), onde percecionar e entender os objetos para além da sua morfologia, função e utilização, poderá ser essencial para a produção de significados mais amplos, refletindo não só a história, mas também a cultura e agentes sociais.

Conforme a Fig. 2 sistematiza, entender as experiências e processos infocomunicacionais em museus é promover um processo científico que determine e valide a produção informacional, a representação dos conteúdos e sua organização (Silva, 2010), de acordo com as necessidades inerentes de cada instituição museológica e todas as suas influências. 


\section{PROCESSOS INFOCOMUNICACIONAIS}

\section{COLEÇÕES E OBJETOS EM MUSEUS}

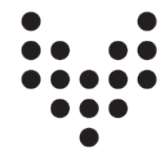

HISTÓRIA

E BIOGRAFIA

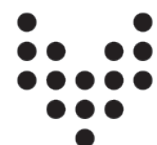

CONTEXTOS

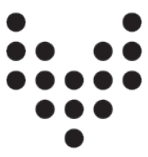

PROVENIÊNCIA

E PRODUÇÃO

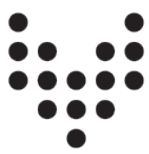

RELAÇÕES

Fig. 2 - Possíveis relações complexas a partir das coleções e objetos em museus. (C Bárbara Andrez, 2021

Não se trata somente de proceder à recolha nostálgica de objetos como testemunhos de proveniência, mas sim pensar nos mecanismos expositivos e ações museológicas como atividades que não são neutras, mas relevantes para a transmissão de relações entre sociedades a partir das coleções que constituem/gerem e expõem.

\section{Considerações finais}

É concludente afirmar que os processos de infocomunicação são intrínsecos à atividade humana, uma vez que decorrem da aglutinação dos conceitos de informação e de comunicação, essenciais para a partilha e retenção de conhecimento, sem os 
quais os indivíduos não conseguem interagir, nem produzir significância. Então, pensar nestes processos em museus é fomentar novas dimensões complexas, em sistemas orgânicos influenciados por fatores internos e externos nas próprias instituições. Estas reflexões paradigmáticas à volta de um pensamento complexo, permitem questionamentos válidos e melhorias, através do recurso a estratégias que possibilitam, depois de identificados, a mitigação de problemas sistémicos, melhorando também a consolidação da transmissão e retenção de conhecimentos informais, tão fundamentais à missão das instituições museológicas.

Assim, potenciar a informação e a comunicação sobre coleções e os artefactos e criações artísticas que as constituem em instituições museológicas é promover relações, desenvolver capacidades, preservar a história para o futuro e, sobretudo, garantir um acesso democratizado à formulação e retenção de conhecimentos informais, através do acesso ao património material e imaterial.

\section{Agradecimentos}

A autora expressa os seus agradecimentos, por todo o apoio prestado, às Prof. Doutoras Maria Manuela Pinto e Paula Menino Homem, FLUP, e à Fundação para a Ciência e a Tecnologia (FCT).

\section{Referências}

- Blair, A., Duguid, P., Goeing, A.-S., \& Grafton A. (Eds.) (2021). Information: A Historical Companion. New Jersey, Oxfordshire: Princeton University Press.

- Cambridge University Press (2021). Process. In Cambridge Dictionary. Disponível a 13 de junho, 2021, em: https://dictionary.cambridge.org/pt/dicionario/ingles/process 
- Collins (2021). Process. In Collins English Thesaurus. Disponível a 13 de junho, 2021, em: https://www.collinsdictionary.com/dictionary/englishthesaurus/process\#process__ 1

- Gouveia, L. B., \& Silva, A. M. d. (2020). A infocomunicação ou a convergência das Ciências da Informação e da Comunicação para um objeto comum. Páginas A\&B, S.3(№ Especial), 15-33. https://doi.org/10.21747/21836671/pag2020a2

- ICOM Portugal (2015, 19 de março). Definição: Museu. Disponível em: https://icom-portugal.org/2015/03/19/definicao-museu/

- Kopytoff, I. (1986). The cultural biography of things: commoditization as process. In A. Appadurai (Ed.), The Social Life of Things (pp. 64-91). Cambridge: Cambridge University Press.

- Morin, E. (2005). Introdução ao Pensamento Complexo. Porto Alegre: Editora Meridional.

- Passarelli, B., Ribeiro, F., Oliveira, L., \& Mealha, Ó. (2014). Identidade conceitual e cruzamentos disciplinares. In E. Senac (Ed.), E-Infocomunicação (pp. 79-121). São Paulo: Senac - Serviço Nacional de Aprendizagem Comercial.

- Pearce, S. (1994). Interpreting Objects and Collection. London, New York: Routlegde.

- Silva, A. M. d. (2006). A Informação: Da Compreensão do Fenómeno e Construção do Objecto Científico. Porto: Edições Afrontamento.

- Silva, A. M. d. (2010). A pesquisa e as suas aplicações em ciência da informação: implicações éticas. In G. H. d. A. Freire (Ed.), Simpósio Brasileiro de Ética da Informação Ética da Informação: Conceitos, Abordagens, Aplicações (pp. 106125). João Pessoa, PB: Ideia Editora Ltda.

- Wolton, D. (2009). Informer N'Est Pas Communiquer. Paris: CNRD Éditions. 